\title{
Factors associated with inadequate diagnosis of COPD: On-Sint cohort analysis
}

\author{
This article was published in the following Dove Press journal: \\ International Journal of COPD \\ 18 May 2015 \\ Number of times this article has been viewed
}

\author{
Alberto Fernández-Villar ${ }^{1}$ \\ José Luis López-Campos ${ }^{2,3}$ \\ Cristina Represas Represas' \\ Lucía Marín Barrera ${ }^{3}$ \\ Virginia Leiro Fernández' \\ Cecilia López Ramírez ${ }^{3}$ \\ Ricard Casamor ${ }^{4}$ \\ 'Department of Pneumology, \\ Complexo Hospitalario de Vigo, \\ Instituto de Investigación Biomédica \\ de Vigo, Vigo, ${ }^{2}$ Medical-Surgical Unit \\ of Respiratory Diseases, Instituto \\ de Biomedicina de Sevilla, Hospital \\ Universitario Virgen del Rocío/ \\ Universidad de Sevilla, Seville, \\ ${ }^{3}$ Centro de Investigación Biomédica \\ en Red de Respiratorio, Instituto \\ de Salud Carlos III, Madrid, ${ }^{4}$ Medical \\ Department, Novartis Farmacéutica, \\ Barcelona, Spain
}

Correspondence: Alberto FernándezVillar

Servicio de Neumología. Complexo Hospitalario de Vigo. Pizarro, 22. 3620I. Vigo. Spain

Tel +34986816069

$\mathrm{Fax}+34986816029$

Email alberto.fernandez.villar@sergas.es
Background: The purpose of this study was to evaluate the frequency of inadequate diagnosis and factors predictive of this in patients with chronic obstructive pulmonary disease (COPD) participating in the On-Sint study.

Methods: The On-Sint cohort was recruited for a multicenter observational study in which 356 physicians ( $71.6 \%$ from primary care) included adult patients who had been diagnosed with COPD. Patients' clinical and functional information since diagnosis and details for the recruiting physicians were collected from patient files and at the inclusion visit. We performed a multivariate analysis to evaluate the influence of these variables on diagnostic inadequacy (absence of postbronchodilator forced expiratory volume in one second/forced vital capacity $\left[\mathrm{FEV}_{1} / \mathrm{FVC}\right]<0.70$ or, if this value was missing, prebronchodilator $\mathrm{FEV}_{1} / \mathrm{FVC}<0.70$ ).

Results: In total, 1,214 patients were included in the study. The patients had a mean age of $66.4 \pm 9.7$ years and $78.8 \%$ were male. In total, $51.3 \%$ of patients did not have an obstructive spirometry performed, and $21.4 \%$ had a normal or non-obstructive spirometry pattern. Patientrelated factors associated with inadequate diagnosis were: years since diagnosis (odds ratio [OR] $1.03,95 \%$ confidence interval [CI] 1.01-1.05), number of exacerbations in the previous year (OR $1.01,95 \%$ CI 1.01-1.02), comorbidities (OR 1.05, 95\% CI 1.01-1.015), and obesity (OR 1.06, $95 \%$ CI $1.02-1.10$ per $\mathrm{kg} / \mathrm{m}^{2}$ of body mass index), while a longer smoking history (OR 0.98 , 95\% CI 0.97-0.99 for each pack/year) and short-acting or long-acting bronchodilator therapy (OR 0.61, 95\% CI 0.44-0.76 and OR 0.46, 95\% CI 0.27-0.76, respectively) were inversely related. With regard to physician-related variables, being followed up by primary care physicians (OR 3.0, 95\% CI 2.11-4.34) and in rural centers (OR 1.63, 95\% CI 1.12-2.38) were positively associated with an inadequate diagnosis, while having regular follow-ups in the most severe cases (OR $0.66,95 \%$ CI $0.46-0.93$ ) and use of quality of life questionnaires (OR $0.55,95 \%$ CI 0.40-0.76) were negatively associated.

Conclusion: Diagnosis of COPD was inadequate in half of the patients from the On-Sint cohort. There were multiple factors, both patient-related and physician-related, associated with this misdiagnosis.

Keywords: chronic obstructive pulmonary disease, diagnosis, spirometry

\section{Introduction}

Chronic obstructive pulmonary disease (COPD) is one of the most prevalent and lethal chronic diseases, and generates significant health care costs. ${ }^{1-3}$ In recent years, epidemiological studies indicate that the disease is not only significantly underdiagnosed, but also frequently inaccurately diagnosed. ${ }^{4,5}$ The diagnosis of COPD is based on the patient's history of exposure to inhaled noxious particles or gases, primarily tobacco, the presence of respiratory symptoms, and detection of an airway obstruction that is not fully reversible. ${ }^{1,2}$ Spirometry is therefore crucial for an accurate diagnosis, and the results of this test play a fundamental role in classification of disease severity and 
phenotypic characterization of patients. ${ }^{1,2}$ However, many patients are diagnosed with COPD based solely on their medical history and on a physical examination that is usually very nonspecific, without a diagnostic confirmation using spirometry to show airflow obstruction..$^{5-8}$ Recent studies have shown that only $30 \%-50 \%$ of patients diagnosed with COPD have a spirometry test. ${ }^{5-14}$ This inadequate diagnosis can lead to inappropriate drug prescriptions that come with risks to patients, costs to the health care system, and delays in treating other possible causes of the patient's symptoms. ${ }^{4,9,11,14}$ Knowledge of the factors associated with an improper diagnosis of COPD could help establish improvement strategies directed at minimizing this problem. Although there have been several published studies focusing on this issue in the past, they were very heterogeneous and few of them systematically analyzed potential predictive factors, not only those related to patient clinical and epidemiological characteristics, but also those related to physician management practices, which may also influence diagnostic accuracy. ${ }^{7-14}$

On-Sint (Clinical Presentation, Diagnosis, and Course of COPD) was an observational, nationwide, real-life cohort study performed in Spain between 2011 and 2013 that evaluated clinical conditions upon diagnosis of COPD and their influence on progression of the disease. By using the OnSint cohort, the aim of the present analysis was to evaluate the association between a large number of patient-related sociodemographic and clinical variables, as well as physicianrelated sociodemographic variables and management practices, and an inadequate diagnosis of the disease.

\section{Materials and methods}

The On-Sint cohort was recruited between 2011 and 2013 in a multicenter observational study that aimed to investigate the timing of COPD diagnosis and its management in real-life clinical practice. In the study, 356 Spanish primary care physicians and pulmonologists recruited both male and female patients at least 40 years of age with a $\geq 10$ packyear smoking history, who had a COPD diagnosis in their medical history and who were under regular follow-up by their primary care doctors or pulmonologists. The number of participating physicians in each region was proportional to the population of the region in Spain. Patients who did not give their written informed consent to participate in the study and those who were involved in other research projects were excluded.

Participating physicians completed a standardized paper case report form with data based on an exhaustive review of the medical history and on a personal interview with each patient during consultation.

The patient information collected included: history of exposure to risk factors (smoking and exposure to other substances such as inorganic dusts or biomass); signs or symptoms at the time of diagnosis (such as dyspnea, chronic cough, and chronic phlegm production); frequency and severity of exacerbations; comorbidities included in the Charlson Comorbidity Index, together with other comorbidities, such as hypertension, dyslipidemia, or sleep apnea; other respiratory symptoms; and anthropometric and sociodemographic data. The degree of dyspnea was evaluated using the modified Medical Research Council (mMRC) dyspnea scale. In addition, to evaluate the impact of the disease on health-related quality of life (HRQoL), all participants completed the COPD Assessment Test at inclusion.

We recorded the availability of spirometry data at inclusion and at the time of diagnosis. If available, we collected the values for forced expiratory volume in one second $\left(\mathrm{FEV}_{1}\right)$, forced vital capacity $(\mathrm{FVC})$, and $\mathrm{FEV}_{1} / \mathrm{FVC}$ ratio both prebronchodilation and postbronchodilation.

Information on pharmacological and non-pharmacological maintenance treatment (home oxygen therapy, rehabilitation) was also collected. The therapeutic categories included were: short-acting bronchodilators (beta agonists and/or muscarinic agonists), long-acting bronchodilators (beta agonists and/or muscarinic agonists), inhaled corticosteroids, methylxanthines, and mucolytics.

The physicians completed an ad hoc questionnaire including: sociodemographic data; consultation setting (primary care or pneumology, as well as urban or rural location); work experience in years; workload as measured by total number of consultations per week and total number of COPD patients attended per week; utilization of HRQoL questionnaires (COPD Assessment Test, St George's Respiratory Questionnaire, Chronic Respiratory Disease Questionnaire, Validation of the Airways Questionnaire 20); and use of multidimensional scaling (BODE Index) and dyspnea scales (Medical Research Council).

Diagnostic adequacy was assessed by analyzing spirometric data at the time of diagnosis. Inadequate diagnosis was defined as the absence of spirometry testing with postbronchodilator $\mathrm{FEV}_{1} / \mathrm{FVC}<0.70$ at diagnosis or later on during follow-up or, if this value was missing, absence of prebronchodilator $\mathrm{FEV}_{1} / \mathrm{FVC}<0.70$.

All patients and investigators signed an informed consent form specifically designed for the study, which was approved 
by the independent ethics committee of Servicio Gallego de Salud with the directive 2011/359.

\section{Statistical analysis}

Categorical variables are described using their absolute and relative frequencies, while quantitative variables are described by the mean and standard deviation. We evaluated the relationship between all variables possibly related to improper diagnosis and diagnostic inadequacy using the $\chi^{2}$ test for categorical variables and the Student's $t$-test for numerical variables, after Levene's test was used to assess the equality of variances. The associations were considered significant at a $P<0.05$. A binomial multivariate logistic regression analysis was done to investigate the patient-related and physician-related factors associated with an inadequate diagnosis. In this analysis, all variables (related to both patients and physicians) that were significantly associated with inadequate diagnosis in the bivariate analysis were included as independent variables. Results are expressed using the odds ratio (OR) with the $95 \%$ confidence interval (CI). Statistical Package for the Social Sciences version 21 software (IBM Corporation, Somers, NY, USA) was used for all calculations.

\section{Results}

During the study period, we recruited 1,264 patients, of whom 1,214 fulfilled the inclusion criteria and were included in the analysis. A total of 857 (70.6\%) patients were recruited by 263 primary care physicians and 357 (29.4\%) were recruited by 93 pulmonologists. The characteristics of the patients are detailed in Table 1 . Most patients were males aged $\geq 70$ years who had been diagnosed between 5 and 10 years earlier; just over a quarter of them were active smokers and a significant percentage had several comorbidities, which were mainly

Table I Patient characteristics and diagnostic accuracy: bivariate analysis

\begin{tabular}{|c|c|c|c|c|}
\hline Patient characteristics & $\begin{array}{l}\text { Patients } \\
(n=I, 2 \mid 4)\end{array}$ & $\begin{array}{l}\text { Inadequate diagnosis } \\
(n=623)\end{array}$ & $\begin{array}{l}\text { Adequate diagnosis } \\
(n=591)\end{array}$ & $P$-value \\
\hline Age (years)* & $66.4(9.7)$ & $66.0(9.9)$ & $66.8(9.5)$ & 0.14 \\
\hline Male & $955(78.8 \%)$ & $478(76.7 \%)$ & 477 (8I.3\%) & 0.053 \\
\hline Time elapsed since diagnosis (years)* & $8.01(7.2)$ & $9.04(8.2)$ & $6.9(5.7)$ & 0.004 \\
\hline Active smokers & $318(26.5 \%)$ & $167(27.2 \%)$ & I5I (25.7\%) & 0.55 \\
\hline Smoking history (packs/year)* & $36.3(20.8)$ & $32.1(19.3)$ & $40.7(21.4)$ & $<0.0001$ \\
\hline Presence of other COPD risk factors & 231 (19.2\%) & $129(20.9 \%)$ & $102(17.4 \%)$ & 0.12 \\
\hline Body mass index $\left(\mathrm{kg} / \mathrm{m}^{2}\right)^{*}$ & $27.7(4.1)$ & $28.2(3.8)$ & $27.2(4.3)$ & $<0.0001$ \\
\hline Dyspnea (mMRC scale)* & $\mathrm{I} .53(0.8)$ & $1.49(0.8)$ & $\mathrm{I} .59(0.8)$ & 0.10 \\
\hline Presence of chronic sputum & $876(74.2 \%)$ & $450(74.9 \%)$ & $426(76.6 \%)$ & 0.60 \\
\hline Exacerbations in the past year* & $2.32(1.9)$ & $2.52(2.0)$ & $2.11(1.8)$ & $<0.0001$ \\
\hline Hospitalizations in the past year* & $0.08(0.4)$ & $0.1(0.4)$ & $0.05(0.3)$ & 0.55 \\
\hline Score on CAT questionnaire* & $18.3(7.6)$ & $18.4(7.4)$ & I8. I (7.8) & 0.31 \\
\hline Number of comorbidities* & $2.8(1.8)$ & $3.03(1.9)$ & $2.6(1.7)$ & $<0.0001$ \\
\hline Sleep apnea & $258(21.5 \%)$ & 146 (23.7\%) & 112 (19.2\%) & 0.06 \\
\hline Hypertension & 747 (63.2\%) & $404(65.7 \%)$ & $353(60.5 \%)$ & 0.06 \\
\hline Heart failure & 154 (12.7\%) & $93(14.9 \%)$ & $61(10.3 \%)$ & 0.01 \\
\hline Peripheral artery disease & $129(10.6 \%)$ & $76(12.2 \%)$ & $53(10.6 \%)$ & 0.06 \\
\hline Cerebrovascular disease & $6 \mathrm{I}(5.0 \%)$ & $34(5.5 \%)$ & $27(4.6 \%)$ & 0.47 \\
\hline Gastroduodenal ulcer & 106 (8.7\%) & $65(10.4 \%)$ & $4 \mathrm{I}(6.9 \%)$ & 0.03 \\
\hline Chronic liver disease & $5 \mathrm{I}(4.2 \%)$ & $29(4.7 \%)$ & $22(3.7 \%)$ & 0.41 \\
\hline Diabetes & $27 \mid(22.3 \%)$ & $159(24.1 \%)$ & 121 (20.5\%) & 0.13 \\
\hline Dyslipidemia & $603(50.3 \%)$ & $334(54.3 \%)$ & $269(46.1)$ & 0.005 \\
\hline Active malignancy & $48(4.0 \%)$ & $19(3 \%)$ & $29(4.9)$ & 0.09 \\
\hline Treated with short-acting bronchodilators & $514(42.3 \%)$ & $239(38.4 \%)$ & $275(46.5 \%)$ & 0.004 \\
\hline Treated with long-acting bronchodilators & I,073 (88.4) & $525(84.3 \%)$ & $548(92.7 \%)$ & $<0.0001$ \\
\hline Treated with inhaled corticosteroids & $635(52.3 \%)$ & $302(48.5 \%)$ & $333(56.3 \%)$ & 0.006 \\
\hline Treated with methylxanthines & $69(5.7 \%)$ & $31(5.0 \%)$ & $38(6.4 \%)$ & 0.27 \\
\hline Treated with mucolytics & $331(27.1 \%)$ & $178(28.6 \%)$ & $173(25.9 \%)$ & 0.29 \\
\hline Home oxygen therapy & 181 (15.4\%) & $97(16.2 \%)$ & $84(14.5 \%)$ & 0.42 \\
\hline Pulmonary rehabilitation & $18 \mid$ (15.9\%) & 93 (I5.7\%) & $88(15.6 \%)$ & 0.94 \\
\hline
\end{tabular}

Note: *Exressed as mean (standard deviation).

Abbreviations: COPD, chronic obstructive pulmonary disease; mMRC, modified Medical Research Council; CAT, COPD Assessment Test. 
cardiovascular and metabolic. Patients experienced a high frequency of exacerbations, with $32.6 \%$ having been hospitalized during the past year; 78.5\% had grade 1-2 dyspnea according to the mMRC dyspnea scale. In almost half of the sample, the disease had a high or very high impact on their HRQoL. The majority of patients were treated with long-acting bronchodilators and approximately 50\% were receiving short-acting bronchodilators and inhaled corticosteroids.

The questionnaire about physician's characteristics (Table 2) was completed by 288 individuals (80.8\%). Most of the participating physicians were male, with an average age of 50 years, working primarily in urban (59.3\%) primary care centers (71.7\%), and had extensive professional experience (92.5\% had over 10 years' experience). In total, $81.7 \%$ of physicians attended more than 50 patients a week, and on average, $16.7 \%$ (11.9) of these were COPD-diagnosed patients; $34.2 \%$ reported that they used a HRQoL questionnaire and $41.1 \%$ used multidimensional scales or dyspnea scales in their routine management of the disease. In cases of severe COPD, $69.8 \%$ of the physicians scheduled regular follow-up visits.

A total of 837 patients $(69 \%)$ had not undergone postbronchodilator spirometry at the time of their diagnosis, although this number decreased to $772(63.6 \%)$ if spirometry tests were considered even in the absence of a bronchodilator response evaluation; 623 patients $(51.3 \%)$ did not have an obstructive spirometry recorded during follow-up. Of the $591(48.7 \%)$ patients who had undergone an obstructive spirometry test, the mean expected $\mathrm{FEV}_{1} \%(\mathrm{SD})$ were: $\mathrm{FEV}_{1}$ 55.7\% (19.7), FVC 75.1\% (20.0), and FEV ${ }_{1} / \mathrm{FVC} 54.4$
(11.4); 260 patients $(21.4 \%)$ had a normal or non-obstructive spirometry result.

The multivariate analysis evaluating factors independently associated with the absence of an obstructive spirometry is shown in Table 3, such factors were time since diagnosis, body mass index, number of exacerbations in the previous year, and number of comorbidities. Conversely, increased cumulative tobacco consumption or treatment with bronchodilators, particularly long-acting ones, were negatively associated with inadequate diagnosis of COPD. Inadequate diagnosis was also associated with the management of the patient by a primary care physician as well as the patient being followed up in a rural setting. Patients recruited by physicians who recommend regular follow-up visits in cases of severe COPD and by physicians who routinely use HRQoL questionnaires were less likely to be inadequately diagnosed.

\section{Discussion}

This study shows that $64 \%$ of patients over 40 years of age with a significant smoking history diagnosed with COPD in our setting did not have a single spirometry test in their medical history. In cases where patients underwent a spirometry test, the result was normal or non-obstructive in almost 50\% of cases. Furthermore, several patient-related and physicianrelated factors were associated with inadequate diagnosis.

Our study confirms several findings by previous researchers, ${ }^{4-6,8-16}$ and also adds some novel associations that have not been described before. Accordingly, we provide a new, updated and comprehensive analysis of factors associated with misdiagnosis. This information may help

Table 2 Physician characteristics and diagnostic accuracy: bivariate analysis

\begin{tabular}{|c|c|c|c|c|}
\hline Physician characteristics & $\begin{array}{l}\text { Patients included } \\
(\mathrm{n}=962)\end{array}$ & $\begin{array}{l}\text { Inadequate diagnosis } \\
(n=5 \mid 3)\end{array}$ & $\begin{array}{l}\text { Adequate diagnosis } \\
(n=449)\end{array}$ & $P$-value \\
\hline Age (years)* & $53.2(8.2)$ & $54.4(7.5)$ & $51.8(8.8)$ & $<0.0001$ \\
\hline Male & $833(86.6 \%)$ & 452 (88. I\%) & 381 (84.9\%) & 0.14 \\
\hline Primary care physician & $682(70.9 \%)$ & $434(84.6 \%)$ & $248(55.2 \%)$ & $<0.0001$ \\
\hline Rural care center & $236(24.7 \%)$ & $159(31.4 \%)$ & $77(17.1 \%)$ & $<0.0001$ \\
\hline Experience $>10$ years & $881(92.6 \%)$ & $483(95.5 \%)$ & $398(89.4 \%)$ & $<0.0001$ \\
\hline \multicolumn{5}{|l|}{ Patients seen each week } \\
\hline$\leq 50$ & $176(18.2 \%)$ & $65(12.7 \%)$ & | | | (24.7\%) & Reference \\
\hline $51-100$ & $243(25.3 \%)$ & 110 (2I.4\%) & $133(29.6 \%)$ & 0.08 \\
\hline$>100$ & $543(56.5 \%)$ & $338(65.9 \%)$ & 205 (45.7\%) & $<0.0001$ \\
\hline Patients with COPD seen each week* & $17.6(10.9)$ & $15.8(8.4)$ & $16.8(11.0)$ & 0.21 \\
\hline Schedules follow-up visits in severe COPD cases & $674(72.9 \%)$ & $323(62.2 \%)$ & $351(80.5 \%)$ & 0.008 \\
\hline Uses quality of life questionnaires for COPD patients & $327(34.1 \%)$ & 149 (29\%) & $178(40.0 \%)$ & $<0.0001$ \\
\hline $\begin{array}{l}\text { Performs a multidimensional assessment or uses } \\
\text { dyspnea scale }\end{array}$ & $562(59.1 \%)$ & $257(51.1 \%)$ & $305(68.2 \%)$ & $<0.0001$ \\
\hline
\end{tabular}

Note: *Expressed as the mean (standard deviation).

Abbreviation: COPD, chronic obstructive pulmonary disease. 
Table 3 Multivariate analysis of factors related to inadequate diagnosis

\begin{tabular}{|c|c|c|c|}
\hline Variable & Adjusted OR & Cl $95 \%$ & P-value \\
\hline Body mass index $\left(\mathrm{kg} / \mathrm{m}^{2}\right)$ & 1.06 & $1.02-1.10$ & 0.001 \\
\hline Time elapsed since diagnosis (years) & 1.03 & $1.01-1.05$ & 0.01 \\
\hline Number of exacerbations in the past year & 1.01 & $1.01-1.02$ & 0.02 \\
\hline Number of comorbidities & 1.05 & $1.01-1.15$ & 0.04 \\
\hline Number of packs/year & 0.98 & $0.97-0.99$ & 0.002 \\
\hline Treatment with short-acting bronchodilators & 0.61 & $0.44-0.76$ & 0.002 \\
\hline Treatment with long-acting bronchodilators & 0.46 & $0.27-0.76$ & 0.003 \\
\hline Follow-up by primary care physicians & 3.0 & $2.11-4.34$ & $<0.0001$ \\
\hline Rural monitoring center & 1.63 & $1.12-2.38$ & 0.009 \\
\hline Scheduled follow-up visits in severe COPD cases & 0.66 & $0.46-0.93$ & 0.001 \\
\hline Monitoring by a physician who uses quality of life questionnaires & 0.55 & $0.40-0.76$ & $<0.0001$ \\
\hline
\end{tabular}

Abbreviations: COPD, chronic obstructive pulmonary disease; $\mathrm{Cl}$, confidence interval; OR, odds ratio.

further understand inadequate diagnoses and set up specific strategies to address the issue.

Being overweight is one of the most consistent predictors of inadequate diagnosis found in previous studies. ${ }^{9-11}$ This may be particularly important in Spain, where COPD patients are frequently overweight. In addition, there is increasing evidence that weight influences patient HRQoL and is associated with other comorbidities. ${ }^{17}$ Another possible explanation for inadequate diagnosis in these patients could be a misinterpretation of non-obstructive changes more frequently seen on spirometry in overweight patients. Time elapsed since diagnosis is a factor that has rarely been analyzed in previous reports.

Our results give some new information on previous controversial and contradictory findings. We found no association between inadequate diagnosis and patient age, in line with recent work. ${ }^{14}$ However, other reports show conflicting results, with some finding a significant association with age $\mathrm{e}^{10,12,13}$ and others not. ${ }^{6,11}$ A similar disparity of results has been observed for smoking status. This study did not show an association between active smoking and inadequate diagnosis, whereas cumulative exposure to tobacco showed a negative association with inadequate diagnosis in previous reports. ${ }^{6,11}$

The influence of comorbidities on correct diagnosis is worth mentioning. ${ }^{10,12-14}$ A recent study showed a cumulative association between number of comorbidities and the probability of inadequate diagnosis, ${ }^{14}$ which is consistent with the findings of our study. Diagnostic accuracy is one of the key elements in the care models for chronic patients in whom respiratory, cardiovascular, and metabolic diseases frequently coexist. ${ }^{5}$ In addition, symptoms of some of these comorbidities may overlap with those of COPD. Accordingly, it is very important that the clinician in charge includes COPD as a potential diagnosis when assessing the patient's symptoms.
The relationship between number of exacerbations in the previous year and correct diagnosis is also relevant. This is likely due to physicians intensifying COPD treatment (by means of oral corticosteroids, antibiotics, or even hospitalization) during exacerbations, even though many of the patients do not present with airway obstruction. Since the exacerbation is attributed to COPD, a correct diagnosis is prevented and the true underlying reason for the increase in symptoms experienced by the patient is overlooked. ${ }^{14}$

Patients with an inaccurate diagnosis receive bronchodilator therapy less frequently, especially with long-acting bronchodilators, than those who have spirometry. This issue has been the subject of debate in previous publications..$^{9,11,18}$ It is difficult to identify the reasons for this, but one possible explanation is that physicians themselves are aware of the possible inaccuracy of the diagnosis based solely on clinical data, and so treat the disease less vigorously.

Evaluation of physician-related factors is a novelty in the present study. Interestingly, the observed relationships were not as straightforward as the patient-related ones. We found that being enrolled in the study by a primary care physician and not by a pulmonologist and being followed up in a rural setting as opposed to an urban center were the most important predictors of inadequate diagnosis. Moreover, physician practices, such as regular follow-up visits for the most serious cases and use of questionnaires to measure HRQoL were negatively associated with inadequate diagnosis. The specialization of the clinician is definitely the most important physician-related factor mentioned thus far, not only when comparing pulmonologists with primary care physicians, ${ }^{5,6,10}$ but also with other general practitioners. ${ }^{7,15}$ The other study findings are novel and seem to suggest that follow-up of COPD according to the recommendations of clinical practice guidelines is associated with greater diagnostic accuracy, although this relationship could be either 
causal or result from better follow-up as a consequence of correct diagnosis. ${ }^{19}$ Working in a rural center was also independently associated with higher diagnostic inaccuracy, which could be related to more difficult access to high-quality spirometry. ${ }^{14,20,21}$

This study has some limitations that should be discussed, primarily related to its design, which was partially retrospective and relied on adequate recording of clinical, epidemiological, sociodemographic, and management data by the physicians responsible for patient follow-up, which could have introduced some bias. However, the results found with regard to the frequency of inadequate diagnosis are consistent with most studies published thus far. ${ }^{5-14}$ Another potential weakness may be the criterion that we used to assess whether diagnosis was adequate, ie, the $\mathrm{FEV}_{1} / \mathrm{FVC}$ ratio. We used the postbronchodilator value and also, if this parameter was missing, the prebronchodilator value, which occurred in a little over $7 \%$ of the patients. In this regard, we must mention that many patients were diagnosed before the recommendations of scientific societies considered bronchodilator testing essential for diagnosis, so in these cases, the absence of a postbronchodilator value was not inadequate at the time when patients were diagnosed. Further, we found no significant differences in the study results between patients with and without a postbronchodilator test available (data not shown). There has been great variability between the studies published to date with regard to the above-mentioned issues in terms of sample size, design, inadequate diagnosis factors considered, variables included, and background of patients. ${ }^{5,6,8,15}$ In some population-based studies, the definition of diagnostic accuracy was based on the availability of spirometry, without assessing whether or not this test showed an obstruction. In this regard, our study and previous ones have shown that between $20 \%$ and $35 \%$ of COPD patients who have undergone a spirometry test have a normal or nonobstructive pattern. ${ }^{4,5,7}$

A potential strength of this work is that it is the only study conducted to date using a large cohort of patients diagnosed with COPD, managed both by primary care and specialized physicians, and analyzed 40 variables that could influence diagnostic adequacy. These variables are related to both the patients and their managing physicians, and many have not been examined in any of the studies published to date.

In conclusion, this study demonstrates that inadequate diagnosis of COPD is very common, especially in those patients managed in primary care and rural centers and by physicians who do not follow clinical practice guidelines for
COPD. These data should help us prioritize certain patients whose diagnosis should be reviewed.

\section{Disclosure}

This study was supported financially by Novartis, SA. The authors have no other conflicts of interest in this work.

\section{References}

1. Vestbo J, Hurd SS, Agustí AG, et al. Global strategy for the Diagnosis, Management, and Prevention of Chronic Obstructive Pulmonary Disease: GOLD executive summary. Am J Respir Crit Care Med. 2013; 187(4):347-365.

2. GesEPOC Task Force. [Clinical practice guideline for the diagnosis and treatment of patients with chronic obstructive pulmonary disease (COPD) - Spanish guideline for COPD (GesEPOC)]. Arch Bronconeumol. 2012;48 Suppl 1:2-58. Spanish.

3. López-Campos JL, Ruiz-Ramos M, Soriano JB. Mortality trends in chronic obstructive pulmonary disease in Europe, 1994-2010: a joinpoint regression analysis. Lancet Respir Med. 2014;2(1):54-62.

4. Miravitlles M, Soriano JB, García-Río F, et al. Prevalence of COPD in Spain: impact of undiagnosed COPD on quality of life and daily life activities. Thorax. 2009;64(10):863-868.

5. Joo MJ, Au DH, Lee TA. Use of spirometry in the diagnosis of chronic obstructive pulmonary disease and efforts to improve quality of care. Transl Res. 2009;154(3):103-110.

6. Arne M, Lisspers K, Ställberg B, et al. How often is diagnosis of COPD confirmed with spirometry? Respir Med. 2010;104(4):550-556.

7. Pellicer Císcar C, Soler Cataluña JJ, Andreu Rodríguez AL, Bueso Fabra J; on behalf of the EPOC group, Valencia Society of Respiratory Medicine. [Diagnosis of COPD in hospitalised patients]. Arch Bronconeumol. 2010;46(2):64-69. Spanish.

8. Pozo-Rodríguez F, López-Campos JL, Alvarez-Martínez CJ, et al. Clinical audit of COPD patients requiring hospital admissions in Spain: AUDIPOC study. PLoS One. 2012;7(7):e42156.

9. Miravitlles M, de la Roza C, Naberan K, Lamban M, Gobartt E, Martin A. Use of spirometry and patterns of prescribing in COPD in primary care. Respir Med. 2007;101(8):1753-1760.

10. Gershon AS, Hwee J, Croxford R, Aaron SD, To T. Patient and physician factors associated with pulmonary function testing for COPD: a population study. Chest. 2014;145(2):272-281.

11. Walters JA, Walters EH, Nelson M, et al. Factors associated with misdiagnosis of COPD in primary care. Prim Care Respir J. 2011;20(4):396-402.

12. Zwar NA, Marks GB, Hermiz O, et al. Predictors of accuracy of diagnosis of chronic obstructive pulmonary disease in general practice. Med J Aust. 2011;195(4):168-171.

13. Collins BF, Ramenofsky D, Au DH, Ma J, Uman JE, Feemster LC. The association of weight with the detection of airflow obstruction and inhaled treatment among patients with a clinical diagnosis of COPD. Chest. 2014;146(6):1513-1520.

14. Collins BF, Feemster LC, Rinne S, Au DH. Factors predictive of airflow obstruction among veterans with presumed empiric diagnosis and treatment of COPD. Chest. 2015;147(2):369-376.

15. Yu WC, Fu SN, Tai EL, et al. Spirometry is underused in the diagnosis and monitoring of patients with chronic obstructive pulmonary disease (COPD). Int J Chron Obstruct Pulmon Dis. 2013;8:389-395.

16. Joo MJ, Lee TA, Weiss KB. Geographic variation of spirometry use in newly diagnosed COPD. Chest. 2008;134(1):38-45.

17. García-Rio F, Soriano JB, Miravitlles M, et al. Impact of obesity on the clinical profile of a population-based sample with chronic obstructive pulmonary disease. PLoS One. 2014;9(8):e105220.

18. Joo MJ, Lee TA, Au DH, Fitzgibbon ML, Weiss KB. Medication use patterns associated with spirometry in diagnosing COPD. COPD. 2008; 5(6):360-368. 
19. Salinas GD, Williamson JC, Kalhan R, et al. Barriers to adherence to chronic obstructive pulmonary disease guidelines by primary care physicians. Int J Chron Obstruct Pulmon Dis. 2011;6:171-179.

20. Fernández-Villar A, Torres Durán M, Mosteiro Añón M, et al. Utilización de la espirometría en los Centros de Atención Primaria de Galicia [Use of spirometry in primary care centers in Galicia]. Pneuma. 2005;1:80-84. Spanish.
21. Díaz-Grávalos GJ, Palmeiro-Fernández G, Valiño-López MD, et al. [The adequacy of the diagnostic in chronic obstructive pulmonary disease]. Rev Calid Asist. 2012;27(6):305-310. Spanish.

International Journal of COPD

\section{Publish your work in this journal}

The International Journal of COPD is an international, peer-reviewed journal of therapeutics and pharmacology focusing on concise rapid reporting of clinical studies and reviews in COPD. Special focus is given to the pathophysiological processes underlying the disease, intervention programs, patient focused education, and self management protocols.
Dovepress

This journal is indexed on PubMed Central, MedLine and CAS. The manuscript management system is completely online and includes a very quick and fair peer-review system, which is all easy to use. Visit $\mathrm{http}: / / \mathrm{www}$.dovepress.com/testimonials.php to read real quotes from published authors.

Submit your manuscript here: http://www.dovepress.com/international-journal-of-chronic-obstructive-pulmonary-disease-journal 